\title{
PENERAPAN IoT (INTERNET of THINGS) TERHADAP RANCANG BANGUN SISTEM PERINGATAN BATASAN KECEPATAN DAN PENDETEKSI LOKASI KECELAKAAN BAGI PENGENDARA SEPEDA MOTOR BERBASIS ARDUINO
}

\author{
Mukhlis Sholihin, Suryo Adi Wibowo, Renaldi Primaswara Prasetya \\ Program Studi Teknik Informatika S1, Fakultas Teknologi Industri \\ Institut Teknologi Nasional Malang, Jalan Raya Karanglo km 2 Malang, Indonesia \\ mukhlissholihin423@gmail.com
}

\begin{abstract}
ABSTRAK
Sepeda motor merupakan transportasi yang umumnya banyak digunakan oleh masyarakat dalam bepergian atau bekerja. Berkendara dengan sepeda motor merupakan hal yang praktis untuk menghindari kemacetan pada kawasan perkotaan. Menurut data dari Satlantas Polres Malang, untuk wilayah Kabupaten Malang selama Januari 2020 kemarin, angka laka lantas bertengger di 69 kejadian. Kepala Unit (Kanit) Laka Satlantas Polres Malang, Ipda Agus Yulianto menyampaikan, Januari 2021 terdapat 37 kasus laka lantas di Kabupaten Malang. (Ajeng Jasita Ingtyas, Lionita, 2021). Adapun faktor yang dapat menyebabkan terjadinya kecelakaan tersebut disebabkan oleh pengendara sepeda motor yang ugal-ugalan dan mengendarai kendaraan dengan kecepatan tinggi. Hal ini perlu diperhatikan agar baiknya berkendara tidak melebihi dari $50 \mathrm{~km} / \mathrm{jam}$ pada kawasan perkotaan. Adapun faktor yang dapat menyebabkan terjadinya kecelakaan tersebut disebabkan oleh pengemudi yang ugal-ugalan dan mengendarai kendaraan dengan kecepatan tinggi. Karena hal itu perlu disikapi oleh pengemudi yang setiap hari megendarai kendaraan mereka. Hal ini perlu diperhatikan agar baiknya berkendara tidak melebihi dari 50km/jam pada kawasan perkotaan. Karena jika sudah melebihi batas kecepatan tersebut akan berdampak pada resiko kecelakaan. Dari penelitian tersebut dapat mengembangkan suatu alat yang dapat memberikan informasi kecepatan sepeda motor kepada pengendara. Sensor LM393 digunakan sebagai pendeteksi kecepatatan dengan rata-rata persentase eror 7,71\%. Jika kecepatan sepeda motor tersebut melaju diatas $50 \mathrm{~km} / \mathrm{j}$ maka akan memberikan peringatan kepada pengendara dengan buzzer berbunyi dan sensor MPU6050 digunakan sebagai deteksi nilai kemiringan suatu sepeda motor dengan rentang $60^{\circ}-120^{\circ}$ sebagai batas aman kemiringan sepeda motor. Modul Neo-6M dapat mendeteksi titik lokasi koordinat jika pengendara sepeda motor mengalami kecelakaan dengan baik dengan hasil selisih jarak yang dihasilkan paling dekat adalah 4,44 meter dan selisih jarak paling jauh adalah 10,00 meter dan rata-rata jarak sejauh 6,66 meter. Pada website yang dibuat memiliki fitur monitoring untuk melihat data terbaru dari hasil deteksi sensor. Berdasarkan pengujian terhadap sensor dan fitur pada website monitoring sepeda motor dapat berjalan dan bekerja dengan baik. Berdasarkan pengujian terhadap pengguna diketahui telah sesuai dengan kebutuhan.
\end{abstract}

Kata Kunci : Sepeda motor, Sensor LM393, Sensor MPU6050, Modul Neo6m, Website.

\section{PENDAHULUAN}

Sepeda motor merupakan transportasi yang umumnya digunakan pada pekerja ojek online. Dengan seiring meningkatnya populasi penduduk maka berpengaruh juga terhadap meningkatnya transportasi di jalan raya. Saat ini profesi ojek online cukup banyak diminati oleh orang yang memiliki kendaraan bermotor. Berkendara dengan sepeda motor merupakan hal yang praktis untuk menghindari kemacetan pada kawasan perkotaan.

Menurut data dari Satlantas Polres Malang, untuk wilayah Kabupaten Malang selama Januari 2020 kemarin, angka laka lantas bertengger di 69 kejadian. Kepala Unit (Kanit) Laka Satlantas Polres Malang, Ipda Agus Yulianto menyampaikan, Januari 2021 terdapat 37 kasus laka lantas di Kabupaten Malang. (Ajeng Jasita Ingtyas , Lionita, 2021).

Adapun faktor yang dapat menyebabkan terjadinya kecelakaan tersebut disebabkan oleh pengemudi ojek online yang ugal-ugalan dan mengendarai kendaraan dengan kecepatan tinggi. Karena hal itu perlu disikapi oleh pengemudi ojek online yang setiap hari melakukan pekerjaan mereka. Hal ini perlu diperhatikan agar baiknya berkendara tidak melebihi dari $50 \mathrm{~km} / \mathrm{jam}$ pada kawasan perkotaan. Karena jika sudah melebihi batas kecepatan tersebut akan berdampak pada resiko kecelakaan.

Melihat zaman sekarang teknologi sudah berkembang sangat pesat dan cepat. Apapun pekerjaan manusia dapat digantikan oleh mesin. Semuanya bisa dilakukan dengan mudah dan singkat karena hampir semuanya sudah berbasis Iot. IoT atau kepanjangan dari Internet of Things memiliki beberapa manfaat pada sistem transportasi misalnya dalam mengontrol lalu lintas, mengatur sistem parkir kendaraan dan juga hal lain yang berkaitan dengan keselamatan berkendara di jalan. Karena hal itu peran IoT ini juga penting bagi manusia karena memudahkan kita dalam bekerja dan mengontrol sesuatu dengan baik.

Berdasarkan Dari permasalahan di atas akan dikembangkan suatu alat yang dapat membantu pengemudi untuk meminimalisir terjadinya 
kecelakaan. Alat ini bekerja dengan membaca nilai kecepatan yang dibaca oleh sensor LM393. Jika pengemudi mengendarai kendaraan melebihi batas kecepatan yang telah ditentukan maka akan memberikan peringatan kepada pengendara agar segera mengurangi laju kendaraan tersebut. Alat ini juga nantinya akan menggunakan sensor gyroscope untuk mengetahui pengendara dalam keadaan diam atau kecelakaan berdasarkan nilai kemiringan yang diperoleh dari sensor tersebut. Modul Neo-6m juga akan digunakan dalam sistem ini yang berfungsi sebagai informasi titik lokasi koordinat jika pengendara mengalami kecelakaan. Sistem monitoring ini dapat diakses melalui website yang telah dikembangkan sebagai informasi kepada pengguna. Website digunakan sebagai informasi karena memiliki jangkauan yang sangat luas dan bisa diakses oleh siapa saja,dimana saja, dan kapan saja. Pada perkembangan alat ini semoga dapat membantu pengendara dalam meminimalisir terjadinya kecelakaan dan membantu pengelola ojek online dalam memantau pekerjanya dalam melakukan pekerjaanya dengan baik dan tidak ugal-ugalan di jalan raya.

\section{TINJAUAN PUSTAKA}

\subsection{Penelitian Terdahulu}

Pada penelitian yang dilakukan oleh Aries Suprayogi (2019) dengan judul "Sistem Pendeteksi Kecelakaan Pada Sepeda Motor Berdasarkan Kemiringan Menggunakan Sensor Gyroscope Berbasis Arduino“. Tujuan penelitian ini menyatakan kecelakaan sepeda motor dengan nilai kemiringan $10^{\circ}-50^{\circ}$ untuk sebelah kiri dan kemiringan $130^{\circ}-170^{\circ}$ untuk sebelah kanan. Rancangan sistem ini menggunakan sensor gyroscope yang dapat membaca nilai kemiringan dari motor tersebut. Sebagai media informasinya menggunakan modul GSM SIM900A dengan mengirimkan notifikasi berupa sms pada handphone pengguna.

Pada penelitian yang dilakukan oleh Olivia M. Sinaulan (2015) dengan judul "Perancangan Alat Ukur Kecepatan Kendaraan Menggunakan ATMega 16". Tujuan penelitian ini adalah merancang sebuah alat yang dapat mengukur laju dari kendaraan yang melintasi jalan bebas hambatan. Rancangan sistem ini menggunakan mikrokontroller AVR ATMEGA 16 yang terdiri dari dua sensor cahaya (Light Dipendent Resistor) dan dua pemancar cahaya (Laser) yang berfungsi untuk mendeteksi adanya kendaraan yang melintas.

Pada penelitian yang dilakukan oleh Christianto Wibisono Darmawan (2020) dengan judul "Implementasi Internet of Things Pada Monitoring Kecepatan Kendaraan Bermotor". Tujuan dari penelitian ini adalah merancang sebuah sistem yang dapat memonitoring kecepatan kendaraan yang dapat membantu orang tua dalam mengawasi pengendara kendaraan bermotor.
Rancangan sistem ini menggunakan modul Neo-6M sebagai alat untuk menginformasikan titik koordinat kendaraan yang akan dipantau. Modul ini juga dapat mengkomunikasikan GPS dengan Arduino.

Pada penelitian yang dilakukan oleh Rizky Hermawan (2020) dengan judul "Pemanfaatan Teknologi Internet Of Things Pada Alarm Sepeda Motor Menggunakan Nodemcu LoLin V3 Dan Media Telegram". Tujuan dari penelitian ini adalah untuk membuat suatu peringatan atau alarm pada sepeda motor untuk mencegah terjadinya pencurian dan perampasan sepeda motor. Alat ini menggunakan microcontroller Nodemcu LoLin V3 sebagai pengolah data. Sensor tegangan dipasang pada alat ini untuk mendeteksi nilai tegangan dari suatu rangkaian. Sensor getar juga dipasang pada alat ini untuk mendeteksi adanya suatu getaran pada suatu benda. Sistem ini menggunakan Telegram bot sebagai media untuk komunikasi antar perangkat dan komponen lainnya yang saling terhubung.

Pada penelitian yang dilakukan oleh Nurhalija (2019) dengan judul "Pemanfaatan LM393 IR Sensor Module Sebagai Pengukur Kecepatan Rotasi Berbasis Mikrokontroller". Tujuan dari penelitian tersebut adalah membuat suatu alat yang dapat menghitung suatu kecepatan putaran angular berbasis mikrokontroller. Mikrokontroller yang digunakan dalam pembuatan alat ini adalah Arduino UNO R3. Sensor LM393 digunakan untuk membaca nilai suatu putaran pada motor DC. Nilai yang di baca oleh sensor LM393 tersebut kemudian ditampilkan pada LCD sebagai informasi kecepatan putaran pada motor DC.

Pada penelitian yang dilakukan oleh Stevania Bere (2021) dengan judul "Rancang Bangun Alat Pembuka Dan Penutup Tong Sampah Otomatis Menggunakan Sensor Jarak Berbasis Arduino". Tujuan dari penelitian ini adalah membuat sebuah tong sampah otomatis yang dapat membuka penutup sampah dengan otomatis ketika jarak seseorang melewati kotak sampah $<=30 \mathrm{~cm}$ maka penutup kotak sampah akan terbuka. Alat ini menggunakan sensor ultrasonic yang berfungsi sebagai pendeteksi jarak orang dengan kotak sampah dan motor servo digunakan sebagai pengendali untuk membuka dan menutup kotak sampah. Sistem ini menggunakan media telegram sebagai informasi peringatan jika kotak sampah telah terisi penuh. Dalam penelitian tersebut terdapat kesamaan hal pendukung yang saya buat yaitu program berbasis IoT (Internet of Things).

Pada penelitian yang dilakukan oleh Joseph Dedy Irawan (2017) dengan judul "Ruang Kuliah Pintar Pemantau Tingkat Efektivitas Pembelajaran Yang Dapat Mendeteksi Mahasiswa Bosan Dan Mengantuk". Tujuan dari penelitian ini adalah menerapkan presensi absen siswa dengan menggunakan RFID. Sistem pendeteksi wajah ini dapat meningkatkan efektifitas pembelajaran sehingga jika terjadi proses pembelajaran yang kurang maksimal dapat segera diproses agar 
pembelajaran menjadi maksimal. Dalam penelitian tersebut terdapat kesamaan hal pendukung yang saya buat yaitu program berbasis IoT (Internet of Things).

\subsection{Internet Of Things}

Internet of things atau biasa disingkat dengan Iot merupakan suatu konsep dari progam yang memiliki kemampuan untuk mengirimkan data melalui jaringan internet. Hingga saat ini IoT telah mengalami banyak perkembangan. Karena konsep IoT ini sangat berperan penting bagi pekerjaan dan aktivitas manusia. IoT memilki konsep cara kerja dengan memanfaatkan suatu pemrogaman yang bisa menghasilkan suatu interaksi antara alat yang telah terhubung secara otomatis tanpa campur tangan manusia.

\subsection{Pengertian GPS}

Global Positioning System atau dalam bahasa Indonesia diartikan sebagai sistem pemosisi global merupakan teknologi yang erat kaitannya dengan kehidupan manusia dan umum dikenal dengan istilah GPS menggunakan sinyal dari satelit yang bisa membantu dan mempermudah manusia dalam kegiatan sehari-hari, seperti untuk mengetahui posisi dengan cepat, menentukan rute perjalanan, mengetahui ketinggian suatu tempat, bahkan untuk melihat situasi lalu lintas terkini. Dengan alat ini pengguna dipastikan dapat mengetahui atau melacak posisi banyak hal seperti kendaraan, pasukan/lawan, mobil, dan sebagainya pada keadaan yang sesungguhnya. ( Salsha Pradinda Widjaya, 2020)

\subsection{Pengertian Kecelakaan}

Kecelakaan lalu lintas merupakan suatu kejadian di jalan raya yang tidak diduga maupun disengaja dan melibatkan pengendara motor itu sendiri dan pengguna jalan yang lainnya. Kecelakaan juga dapat mengakibatkan korban jiwa atau bahkan mengakibatkan kerugian harta benda. Banyak faktor yang mempengaruhi terjadinya kecelakaan. Salah satu faktor yang dapat mempengaruhi terjadinya kecelakaan contohnya adalah pengendara motor yang mengendarai motor dengan ugal-ugalan dan melebihi batas kecepatan pada kawasan perkotaan.

\subsection{Telegram}

Secara prinsip sesuai namanya baik telegram dulu den gan telegram sekarang masih memiliki pengertian yang sama, yaitu TELE yang berarti cepat dan GRAM yang memiliki pengertian surat atau jika digabung Telegram adalah surat cepat atau surat kilat, sehingga yang membedakan telegram jaman dulu dengan telegram sekarang adalah media yang digunakan. Karena jika kita berbicara istilah telegram di era digital, maka telegram sekarang sudah tidak lagi menggunakan cara manual melainkan sudah di kemas dalam sebuah aplikasi dengan segala keunggulan fitur yang jauh lebih canggih.( Mas Sun, 2021).

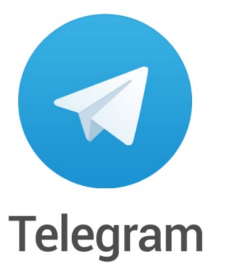

Gambar 1. Media Telegram

\subsection{Arduino UNO R3}

Arduino Uno R3 merupakan sebuah perangkat elektronik yang dirancang untuk bagi para pecinta elektronik dalam mengembangkan kreativitas mereka dalam membuat suatu objek elektronik. Karena perangkat elektronik ini bersifat open source dan dapat berinteraksi dengan berbagai macam sensor dan pengendali. Arduino Uno merupakan sebuah board mikrokontroller yang dikontrol oleh Atmega 328. Untuk menghubungkan perangkat ini dengan computer cukup menggunakan kabel USB dan untuk mensuplainya dengan sebuah AC dan DC atau menggunakan baterai untuk memulainya.

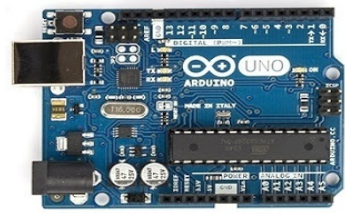

Gambar 2. Arduino UNO R3

\subsection{Modul NEO-6M}

Modul Neo-6m adalah salah satu bagian dari microcontroller. Dengan Modul GPS Ublox neo-6m kita dapat mengetahui lokasi suatu tempat / koordinat dimana modul GPS itu berada, sehingga dengan modul tersebut kita dapat membuat berbagi macam alat yang memerlukan lokasi / titik koordinat. dari modul tersebut kita dapat mendapatkan titik garis lintang / latitude dan garis bujur / longitude.

\subsection{Sensor LM393}

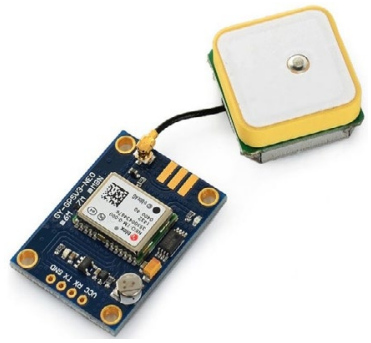

Gambar 3. Modul NEO-6m

Sensor LM393 merupakan sebuah sebuah sensor yang digunakan untuk mengukur kecepatan gerak benda. Pengukuran pada sensor ini mengukur suatu poros atau objek yang berputar pada suatu generator dan menghasilkan suatu tegangan yang seimbang dengan kecepatan putaran objek. 


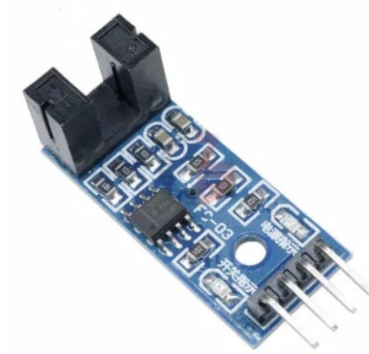

Gambar 4. Sensor LM393

\subsection{Sensor Gyroscope}

Sensor gyroscope merupakan sebuah sebuah sensor yang digunakan untuk mendeteksi bahwa kendaraan dalam kondisi diam atau pada kemiringan tertentu dengan mengetahui nilai kemiringan yang didapatkan oleh sensor. Sebelum digunakan sensor gyroscope harus dilakukan kalibrasi terlebih dahulu.

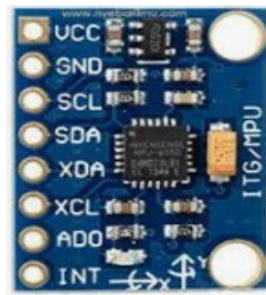

Gambar 5. Sensor Gyroscope

\subsection{Modul ESP 8266}

Modul ESP8266 merupakan sebuah komponen perangkat elektronik yang dibuat untuk solusi jaringan wifi yang lengkap dan menyatu. Komponen ini memiliki kemampuan sebagai penyedia aplikasi dan memiliki chip yang dapat dihubungkan dengan sensor atau aplikasi tertentu. Perangkat elektronik ini memiliki tengangan sebesar 3,6 Volt.

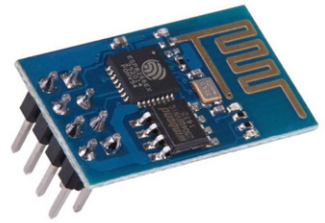

Gambar 6. Modul ESP8266

\section{ANALISIS DAN PERANCANGAN}

\subsection{Analisa kebutuhan Fungsional}

Adapun beberapa kebutuhan yang diperlukan agar sistem yang dibuat dapat berjalan dengan baik.

1. Sistem yang dibuat dapat memantau laju kecepatan kendaraan dan dapat mendeteksi nilai sudut kemiringan sepeda motor yang dibaca oleh sensor.

2. Sistem yang dibuat dapat memberikan informasi titik lokasi koordinat pengendara jika terjadi kecelakaan.
3. Alat yang dibuat dapat memberikan informasi titik lokasi koordinat pengendara kepada pengguna berdasarkan nilai kemiringan sudut kendaraan.

4. Alat yang dibuat mampu memberikan informasi peringatan kepada pengendara jika melebihi batas kecepatan maksimal.

\subsection{Blok Diagram Sistem}

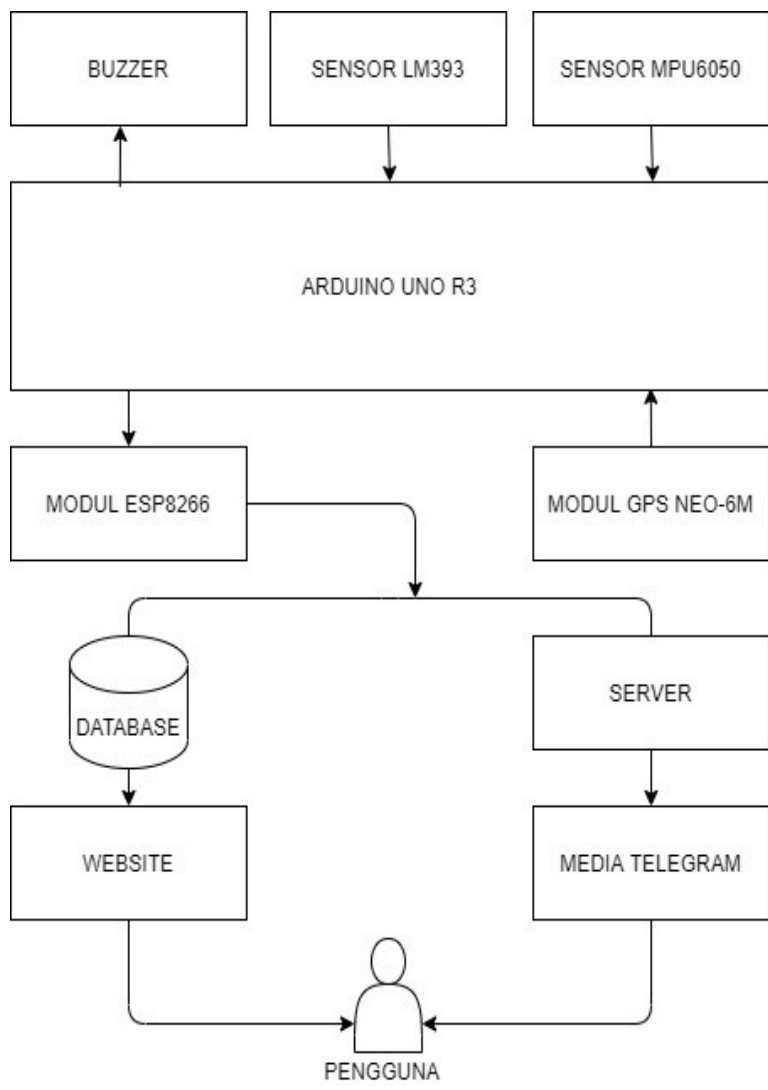

Gambar 7. Blok diagram sistem

Pada sistem ini menggunakan microcontroller yaitu Arduino uno R3 yang digabungkan dengan Modul ESP8266. Sebagai pengontrol dari sistem kerja alat ini menggunakan sensor LM393, buzzer, sensor gyroscope dan modul Neo-6M. Sistem ini bekerja dengan sebuah sensor LM393 yang membaca nilai kecepatan dari kendaran dan sensor gyroscope yang membaca nilai kemiringan sudut pada rentang nilai sudut $60^{\circ}-120^{\circ}$ lalu pada sistem ini buzzer bekerja sebagai output dan modul Neo-6M sebagai sumber informasi titik koordinat jika terjadi kecelakaan. Data tersebut diolah oleh mikrokontroller Arduino R3 lalu data tersebut dikirimkan melalui Modul ESP8266 ke database dan server telegram. Selanjutnya data ditampilkan ke website dan media telegram. 


\subsection{Flowchart Sistem}

Flowchart sistem ini menjelaskan proses berjalananya sistem seperti gambar berikut ini.

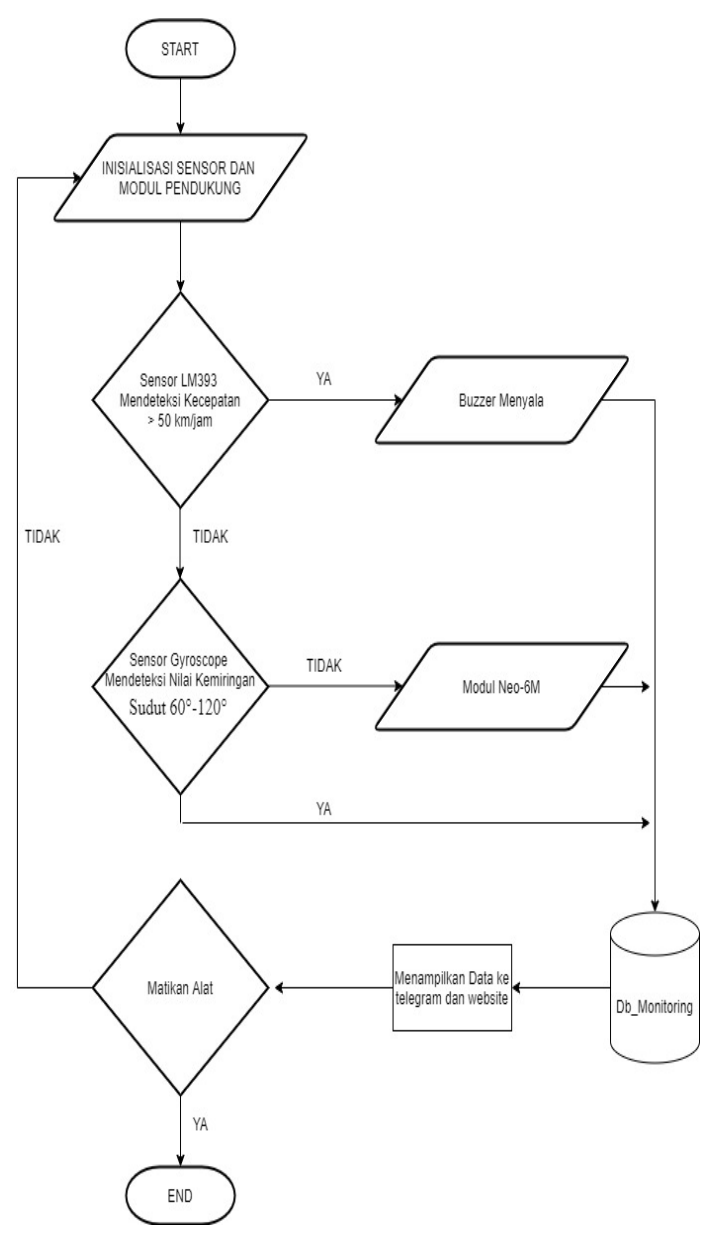

Gambar 8. Flowchart Sistem

Dari alur proses sistem diatas dijelaskan bahwa proses awal yaitu diawali dengan inisialisasi sensor dan modul pendukung. Pada saat sensor LM393 membaca nilai kecepatan $>50 \mathrm{~km} / \mathrm{jam}$ maka buzzer akan menyala dan mengirimkan data kecepatan juga notifikasi peringatan ke dalam database. Jika tidak proses selanjutnya dilakukan oleh sensor gyroscope yang mendeteksi nilai kemiringan sudut di rentang $60^{\circ}-120^{\circ}$. Jika nilai kemiringan yang di deteksi diluar rentang tersebut maka modul Neo-6M akan mengirimkan data lokasi titik koordinat ke database.Data yang telah diperoleh akan dikirimkan ke website secara berkala oleh microcontroller dan ditampilkan pada website dan media telegram.

\subsection{Desain Rangkaian}

Perangkat yang digunakan dalam pembuatan sistem terdiri dari : Arduino uno, Sensor LM393, Buzzer, Sensor MPU6050, Modul GPS Neo-6M dan Modul ESP 8266. Desain rangkaian dapat ditunjukkan pada Gambar berikut.

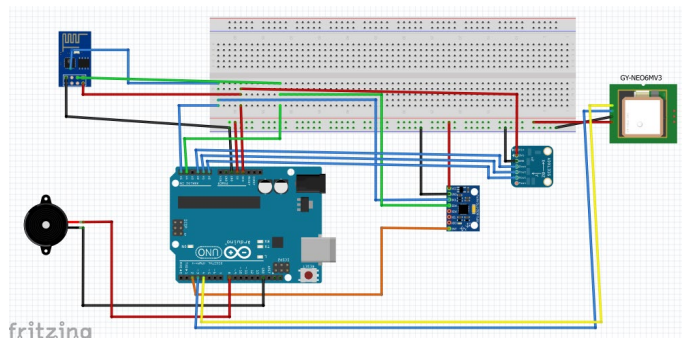

Gambar 9. Design Rancangan

\section{HASIL DAN PEMBAHASAN}

\subsection{Pengujian Website}

Pada pengujian ini web browser yang digunakan yaitu Mozilla Firefox, Google Chrome, dan Microsoft Edge. Pengujian yang dilakukan pada penelitian ini adalah sebagai berikut :

Tabel 1. pengujian website

\begin{tabular}{|c|l|c|r|c|}
\hline No & $\begin{array}{c}\text { Fungsi } \\
\text { Yang } \\
\text { Diuji }\end{array}$ & Google Chrome & $\begin{array}{c}\text { Mozilla } \\
\text { Firefox }\end{array}$ & $\begin{array}{c}\text { Microsoft } \\
\text { Edge }\end{array}$ \\
\hline 1 & Login & $\checkmark$ & $\checkmark$ & $\checkmark$ \\
\hline 2 & $\begin{array}{l}\text { Halaman } \\
\text { Home }\end{array}$ & $\checkmark$ & $\checkmark$ & $\checkmark$ \\
\hline 3 & $\begin{array}{l}\text { Halaman } \\
\text { monitoring }\end{array}$ & $\checkmark$ & $\checkmark$ & $\checkmark$ \\
\hline 4 & $\begin{array}{l}\text { Tampilan } \\
\text { Nilai Sensor } \\
\text { kecepatan }\end{array}$ & $\checkmark$ & $\checkmark$ & $\checkmark$ \\
\hline 5 & $\begin{array}{l}\text { Tampilan } \\
\text { nilai sensor } \\
\text { kemiringan }\end{array}$ & $\checkmark$ & $\checkmark$ & $\checkmark$ \\
\hline 6 & $\begin{array}{l}\text { Tampilan } \\
\text { lokasi titik } \\
\text { koordinat }\end{array}$ & $\checkmark$ & $\checkmark$ & $\checkmark$ \\
\hline 7 & $\begin{array}{l}\text { Tampilan } \\
\text { responsif } \\
\text { pada halaman } \\
\text { monitoring }\end{array}$ & $\checkmark$ & $\checkmark$ & $\checkmark$ \\
\hline 8 & Search Box & $\checkmark$ & $\checkmark$ & $\checkmark$ \\
\hline 9 & $\begin{array}{l}\text { Tombol } \\
\text { Navigasi } \\
\text { Halaman }\end{array}$ & $\checkmark$ & $\checkmark$ & $\checkmark$ \\
\hline
\end{tabular}

keterangan :

$\checkmark$ : Berhasil

$\mathrm{x}$ : Tidak Berhasil.

Berdasarkan hasil uji coba pada tabel di atas bahwa website yang dibuat dapat berjalan dengan baik pada web browser Google Chrome, dan Microsoft Edge.Semua fungsi dapat berjalan dengan baik. Oleh karena itu, fitur pada sistem monitoring yang dikembangkan dapat berjalan dengan baik pada web browser. 


\subsection{Pengujian Sensor MPU6050}

Pengujian Sensor MPU6050 yang dilakukan pada penelitian ini adalah sebagai berikut.

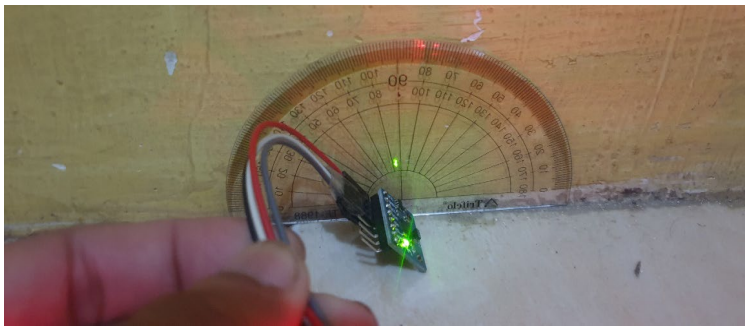

Gambar 10. Pengujian sensor mpu6050

Tabel 2 Pengujian Sensor MPU6050

\begin{tabular}{|c|c|c|}
\hline NO & Sudut Kemiringan & Sensor MPU6050 \\
\hline 1 & $0^{0}$ & 20.00 \\
\hline 2 & $30^{0}$ & 16.00 \\
\hline 3 & $35^{0}$ & 14.00 \\
\hline 4 & $45^{0}$ & 11.00 \\
\hline 5 & $50^{0}$ & 9.00 \\
\hline 6 & $60^{0}$ & 7.00 \\
\hline 7 & $90^{0}$ & 0.00 \\
\hline 8 & $120^{0}$ & -04.00 \\
\hline 9 & $150^{0}$ & -08.00 \\
\hline 10 & $180^{0}$ & -11.00 \\
\hline
\end{tabular}

Berdasarkan hasil pengujian sensor MPU 6050 pada tabel 2 menunjukkan bahwa pengujian berhasil dilakukan. Pengujian dilakukan dengan menggunakan parameter derajat kemiringan sebagai acuan. Rentang derajat kemiringan yang di uji adalah pada rentang $0^{\circ}-270^{\circ}$.

\subsection{Pengujian Sensor LM393}

Pengujian Sensor LM393 yang dilakukan pada penelitian ini adalah sebagai berikut.

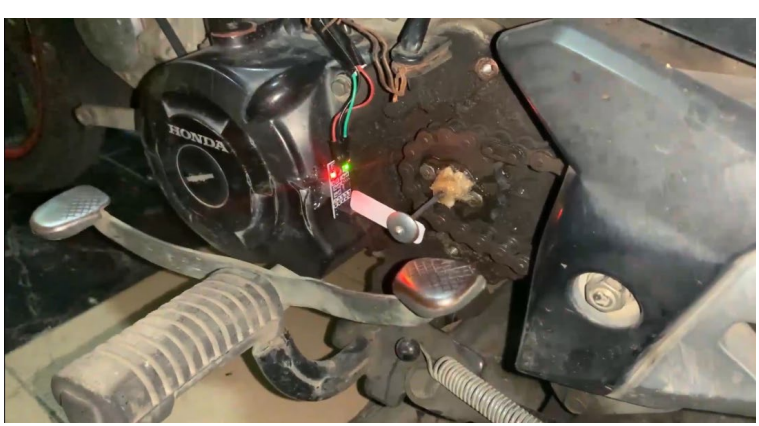

Gambar 11. Pengujian sensor LM393

Tabel 3. Pengujian Sensor LM393

\begin{tabular}{|c|c|c|c|c|}
\hline \multirow{2}{*}{ No } & \multicolumn{2}{|c|}{ Hasil baca sensor LM393 } & \multirow{2}{*}{ Selisih } & $\begin{array}{l}\text { Error } \\
\text { (\%) }\end{array}$ \\
\cline { 2 - 4 } & Sensor LM393 & $\begin{array}{c}\text { Speedo } \\
\text { meter }\end{array}$ & & 9,09 \\
\hline 1 & 20 & 22 & 2 & 9,09 \\
\hline 2 & 20 & 22 & 2 & 8,69 \\
\hline 3 & 21 & 23 & 2 & 8,69 \\
\hline 4 & 21 & 23 & 2 & 3,03 \\
\hline 5 & 32 & 33 & 1 & 38,59 \\
\hline \multicolumn{4}{|c|}{ Total } & 7,71 \\
\hline \multicolumn{4}{|c|}{ Rata - rata kesalahan } \\
\hline
\end{tabular}

Berdasarkan hasil pengujian Sensor LM393 pada tabel 3 menunjukkan bahwa pada pengujian berhasil di lakukan. Setelah dilakukan pengujian terhadap sensor tersebut menunjukkan bahwa total presentase eror yang dihasilkan pada saat pengujian adalah 38,59\%. pengujian Sensor LM393 menggunakan Speedometer diperoleh rata-rata kesalahan sebesar $7,71 \%$ dengan selisih deteksi paling besar pada baris ke -1 dan baris ke - 2 dengan persentase error $9,09 \%$.

\subsection{Pengujian Modul GPS Neo-6M}

Pengujian Modul GPS Neo-6M yang dilakukan pada penelitian ini adalah sebagai berikut.

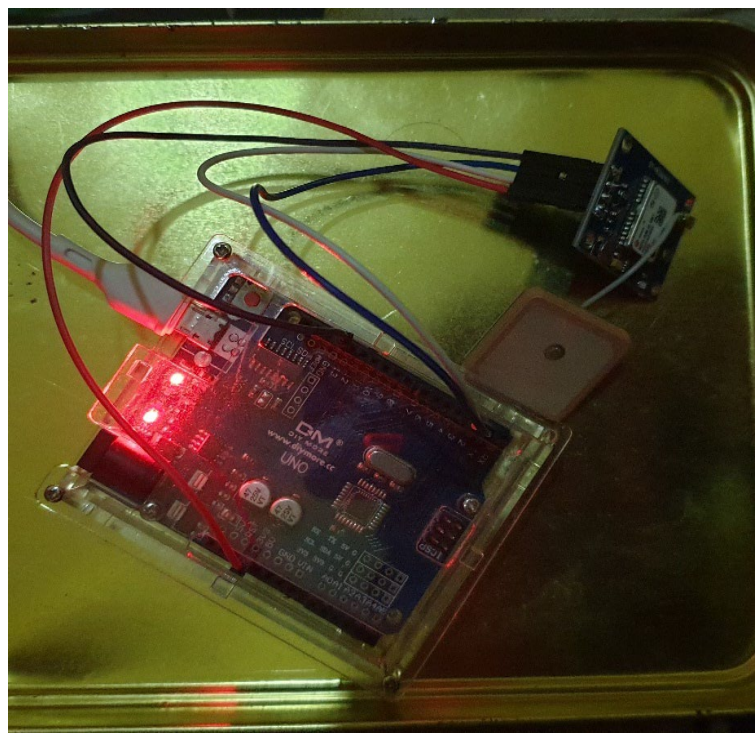

Gambar 12. Pengujian Modul GPS Neo-6M

Tabel 4. Pengujian Modul GPS Neo-6M

\begin{tabular}{|c|c|l|l|l|c|}
\hline \multirow{2}{*}{ No } & \multicolumn{2}{|c|}{ Modul GPS Neo-6m } & \multicolumn{2}{c|}{ Google Maps } & Selisih \\
\cline { 2 - 5 } & Latitude & Longitude & Latitude & Longitude & $(\mathrm{m})$ \\
\hline 1 & -7.90999 & 112.6362 & -7.91004 & 112.6362 & 5,55 \\
\hline 2 & -7.91013 & 112.6362 & -7.91004 & 112.6362 & 10,00 \\
\hline 3 & -7.91013 & 112.6362 & -7.91004 & 112.6362 & 10,00 \\
\hline 4 & -7.91013 & 112.6362 & -7.91004 & 112.6362 & 10,00 \\
\hline 5 & -7.91010 & 112.6362 & -7.91004 & 112.6362 & 6,67 \\
\hline 6 & -7.91010 & 112.6362 & -7.91004 & 112.6362 & 6,67 \\
\hline 7 & -7.91008 & 112.6362 & -7.91004 & 112.6362 & 4,44 \\
\hline 8 & -7.91008 & 112.6362 & -7.91004 & 112.6362 & 4,44 \\
\hline 9 & -7.91008 & 112.6362 & -7.91004 & 112.6362 & 4,44 \\
\hline 10 & -7.91008 & 112.6362 & -7.91004 & 112.6362 & 4,44 \\
\hline \multicolumn{5}{|c|}{ Rata-rata (Meter) } & 6,66 \\
\hline
\end{tabular}

Berdasarkan hasil pengujian Modul GPS Neo 6 $M$ pada tabel 4 menunjukkan bahwa pada pengujian berhasil di lakukan. Hasil pengujian menunjukkan bahwa selisih jarak yang dihasilkan pada saat pengujian modul GPS Neo-6m dengan aplikasi google maps paling dekat adalah 4,4 meter dan selisih jarak paling jauh adalah 10,00 meter dan ratarata jarak 6,6 meter. 


\subsection{Pengujian Buzzer}

Pengujian Sensor buzzer yang dilakukan pada penelitian ini adalah sebagai berikut.

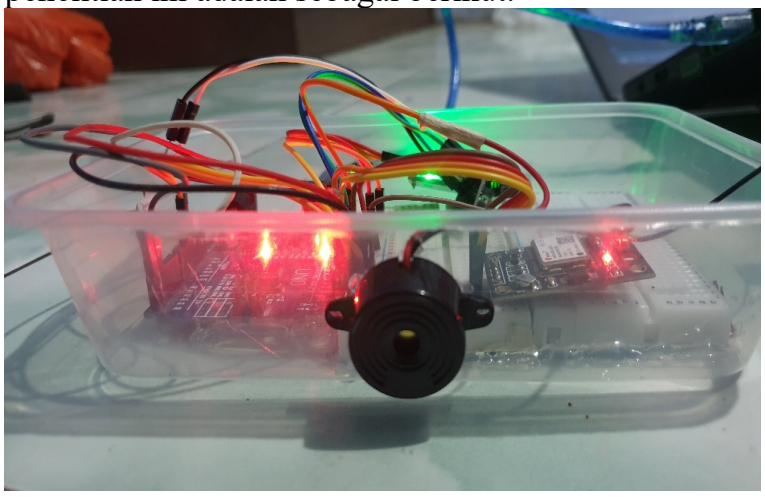

Gambar 13. Pengujian Buzzer

Tabel 5. Pengujian Buzzer

\begin{tabular}{|c|c|c|c|}
\hline NO & Sensor & Nilai Sensor & Buzzer \\
\hline 1 & LM 393 & 23 & Tidak Bunyi \\
\hline 2 & LM 393 & 25 & Tidak Bunyi \\
\hline 3 & LM 393 & 42 & Tidak Bunyi \\
\hline 4 & LM 393 & 45 & Tidak Bunyi \\
\hline 5 & LM 393 & 51 & Bunyi \\
\hline
\end{tabular}

Pengujian buzzer untuk menanggapi hasil deteksi dari sensor LM393 saat mendeteksi nilai data $>50$ maka buzzer akan berbunyi, setelah sensor sudah mendeteksi mendeteksi nilai data $<50$ maka buzzer akan berhenti berbunyi.

\subsection{Pengujian ESP8266}

Pengujian ESP8266 yang dilakukan pada penelitian ini adalah sebagai berikut.

Tabel 6. Pengujian ESP8266

\begin{tabular}{|c|c|c|c|c|}
\hline NO & $\begin{array}{c}\text { Terhubung } \\
\text { Ke AP }\end{array}$ & $\begin{array}{c}\text { Terhubung ke } \\
\text { Server }\end{array}$ & $\begin{array}{c}\text { Data } \\
\text { Sukses } \\
\text { Dikirim }\end{array}$ & $\begin{array}{c}\text { Delay } \\
\text { (detik) }\end{array}$ \\
\hline 1 & Ya & Ya & Ya & 7 \\
\hline 2 & Ya & Ya & Ya & 7 \\
\hline 3 & Ya & Ya & Ya & 7 \\
\hline 4 & Ya & Ya & Ya & 7 \\
\hline 5 & Ya & Ya & Ya & 7 \\
\hline 6 & Tidak & Tidak & Tidak & 7 \\
\hline 7 & Tidak & Tidak & Tidak & 7 \\
\hline 8 & Ya & Ya & Ya & 7 \\
\hline 9 & Ya & Ya & Ya & 7 \\
\hline 10 & Ya & Ya & Ya & 7 \\
\hline
\end{tabular}

Berdasarkan hasil pengujian modul ESP8266 pada tabel 6 menunjukkan bahwa pada pengujian modul ESP8266 ini telah berhasil di lakukan. Setelah dilakukan pengujian terhadap modul ESP8266 tersebut menunjukkan bahwa pengujian komunikasi dan pengiriman data pada saat pengiriman data terdapat 2 data tidak dapat terhubung ke access point, 2 data tidak dapat terhubung ke server, dan 2 data gagal mengirim data ke dalam database. Pada saat melakukan pengiriman data modul esp8266 dapat mengirimkan data setiap 7 detik sekali.

\section{KESIMPULAN DAN SARAN}

\subsection{Kesimpulan}

Dari beberapa tahap pengujian yang telah dilakukan, menghasilkan beberapa kesimpulan diantaranya:

1. Dari hasil pengujian Sensor LM393 diketahui dapat mendeteksi nilai kecepatan dengan ratarata dengan persentase error $7,71 \%$.

2. Dari hasil pengujian Modul GPS dapat mendeteksi titik lokasi koordinat dengan baik dan hasil pengujian menunjukkan bahwa selisih jarak yang dihasilkan pada saat pengujian modul GPS Neo-6m dengan aplikasi google maps paling dekat adalah 4,4 meter dan selisih jarak paling jauh adalah 10,00 meter dan rata-rata jarak 6,6 meter.

3. Modul GPS Neo-6M harus menunggu beberapa menit untuk dapat menangkap sinyal satelit sehingga mendapatkan titik lokasi koordinat longitude dan latitude.

4. Website yang telah dikembangkan dapat berjalan dengan baik pada web browser yang diujikan yaitu Google Chrome, Microsoft Edge, Mozilla Firefox.

5. Dari hasil pengujian Buzzer dapat mengeluarkan bunyi jika sensor LM393 mendeteksi nilai >50 dan buzzer tidak akan mengeluarkan bunyi jika sensor LM393 mendeteksi nilai $<50$.

\subsection{Saran}

Berdasarkan penelitian yang telah dilakukan, maka penulis dapat memberikan saran-saran untuk pengembangan selanjutnya, antara lain :

1. Pengembangan selanjutnya dapat menggunakan sensor yang lebih akurat untuk mendeteksi nilai kecepatan seperti tachometer atau yang lainnya.

2. Dapat menggunakan sensor yang lebih tahan terhadap air dan tidak mudah rusak ketika terkena guncangan.

3. Dapat menggunakan modul GPS dengan tipe Neo-7m yang lebih cepat dalam menangkap sinyal satelit sehingga titik lokasi koordinat lebih cepat terdeteksi dan dapat mendeteksi dalam ruangan tertutup.

4. Pengembangan selanjutnya dapat menerapkan suatu metode timeseries yang dapat mencari ratarata pengendara pada waktu tertentu sering mengendarai kendaraan dengan kecepatan tinggi.

\section{DAFTAR PUSTAKA}

[1] Aries Suprayogi. "Sistem Pendeteksi Kecelakaan Pada Sepeda Motor Berdasarkan Kemiringan Menggunakan Sensor Gyroscope Berbasis Arduino". http://j-ptịk.ub.ac.ịd (2019).

[2] Sinaulan, O.M., Rindengan, Y.D. and Sugiarso, B.A., 2015. Perancangan Alat Ukur Kecepatan Kendaraan Menggunakan ATMega 16. Jurnal Teknik Elektro dan Komputer, 4(3), pp.60-70. 
[3] Darmawan, C.W., Sompie, S.R. and Kambey, F.D., 2020. Implementasi Internet of Things pada Monitoring Kecepatan Kendaraan Bermotor. Jurnal Teknik Elektro dan Komputer, 9(2), pp.91-100.

[4] Hermawan, R. and Abdurrohman, A., 2020. PEMANFAATAN TEKNOLOGI INTERNET OF THINGS PADA ALARM SEPEDA MOTOR MENGGUNAKAN NodeMcu LoLiN V3 DAN MEDIA TELEGRAM. Infotronik: Jurnal Teknologi Informasi dan Elektronika, 5(2), pp.58-67.

[5] Putra, R.A., 2019. Pemanfaatan LM393 IR Sensor Module Sebagai Pengukur Kecepatan Rotasi Berbasis Mikrokontroler. Jurnal Hadron, 1(1), pp.12-15.

[6] Bere, S., Mahmudi, A. and Sasmito, A.P., 2021. RANCANG BANGUN ALAT PEMBUKA DAN PENUTUP TONG SAMPAH OTOMATIS MENGGUNAKAN SENSOR JARAK BERBASIS ARDUINO. JATI (Jurnal Mahasiswa Teknik Informatika), 5(1), pp.357-363.

[7] Dedy Irawan, J., Handoko, F. and Adriantatri, E., 2019. Ruang Kuliah Pintar Pemantau
Tingkat Efektivitas Pembelajaran Yang Dapat Mendeteksi Mahasiswa Bosan Dan Mengantuk. In Seminar Nasional Inovasi dan Aplikasi Teknologi di Industri.

[8] Ajeng Jasita Ingtyas Dan Lionita. "Angka Laka Lantas di Malang Menurun". https://nusadaily.com/regional/2021-angkalaka-lantas-di-malang-menurun.html(2021).

[9] Rahardian P. Paramita. "Batasan Kecepatan Berkendara Yang Wajib Anda Ketahui”. https://beritagar.id/artikel/otogen/bataskecepatan-berkendara-yang-wajib-andaketahui(2015).

[10] Muhammad Robith Adani. "Mengenal Apa Itu Internet of Things dan Contoh Penerapannya".https://www.sekawanmedia.co.i d/pengertian-internet-of-things(2020).

[11] M. Adam Samudra. "4 Faktor Utama Penyebab Kecelakaan di Jalan Raya”. https://www.gridoto.com/read/221030654/4faktor-utama-penyebab-kecelakaan-di-jalanraya(2018). 